\title{
1 Predicting spatial and seasonal patterns of wildlife-vehicle \\ 2 collisions in high-risk areas
}

$4 \quad$ Running title: Spatio-temporal predictors of road-kill

6 Hanh K.D. Nguyen ${ }^{1}$, Jessie C. Buettel ${ }^{2,3}$, Matthew W. Fielding ${ }^{2,3}$, Barry W. Brook ${ }^{2,3^{*}}$

$8{ }^{1}$ School of Technology, Environments and Design, University of Tasmania, Sandy

$9 \quad$ Bay 7005 TAS Australia

$10{ }^{2}$ School of Natural Sciences, University of Tasmania, Sandy Bay 7005 TAS Australia

$11{ }^{3}$ ARC Centre of Excellence for Australian Biodiversity and Heritage

12 * Corresponding author: barry.brook@utas.edu.au 


\section{Abstract}

14 Context: Vehicle collisions with wildlife can injure or kill animals, threaten human

safety, and threaten the viability of rare species. This has led to a focus in roadecology research on identifying the key predictors of 'road-kill' risk, with the goal of

17 guiding management to mitigate its impact. However, because of the complex and context-dependent nature of the causes of risk exposure, modelling road-kill data in ways that yield consistent recommendations has proven challenging.

Aim: Here we used a novel multi-model machine-learning approach to identify the spatio-temporal predictors, such as traffic volume, road shape, surrounding vegetation and distance to human settlements, associated with road-kill risk.

Methods: We collected data on the location, identity and size of each road mortality across four seasons along eight roads in southern Tasmania - a 'road-kill hotspot' of management concern. We focused on three large-bodied and frequently impacted crepuscular Australian marsupial herbivore species, the rufous-bellied pademelon (Thylogale billardierii), Bennett's wallaby (Macropus rufogriseus) and the bare-nosed wombat (Vombatus ursinus). We fit the point-location data using 'lasso-regularization' of a logistic generalized linear model (LL-GLM) and out-of-bag optimization of a decision-tree-based 'random forests' (RF) algorithm.

Results: The RF model, with high-level feature interactions, yielded superior results to the linear additive model, with a RF classification accuracy of $84.8 \%$ for the 871 road-kill observations and a true skill statistic of 0.708 , compared to $61.2 \%$ and 0.205 for the LL-GLM. road posed the highest risk to animals. Seasonally, the frequency of wildlife-vehicle 
37 collisions increased notably for females during oestrus, when they were more

38 dispersive and so had a higher encounter rate with roads.

39 Implications: These findings illustrate the value of using data-driven approaches to

40 predictive modelling, as well as offering a guide to practical management

41 interventions that can mitigate road-related hazards.

42 Keywords: wildlife road mortality, collision risk, road-kill trends, predictive modelling,

43 random forest, lasso regression, habitat features, seasonal influence, sex bias. 


\section{Introduction}

45 Roads and traffic can have severe detrimental impacts on wildlife. The construction

46 of roads can cause habitat fragmentation (Forman and Alexander 1998) and inhibit

47 animal movement across landscapes (Trombulak and Frissell 2000). Among these

48 impacts, wildlife-vehicle collisions could be considered the most observable, due to

49 the visibility of the victims (roadkill). These have been known to increase mortality

50 and therefore threaten population viability (Gibbs and Shriver 2002), with many taxa

51 (mammals, bird, reptiles and even insects) known to be at risk of road-related injury

52 or death (e.g., Elzanowski et al. 2009; Loss et al. 2014; Skorka 2016). Animal

53 collisions can also cause costly damage to vehicles, and in the most extreme cases,

54 human injury or death (Barthelmess 2014). Additionally, many generalist scavengers

55 may benefit from roadside carrion, leading to shifts in the abundance of these

56 species and flow-on effects within the ecosystem (Fielding et al. 2020; Forman and

57 Alexander 1998). Given that the global road network will continue to expand this

century there is an urgent need to understand the threat posed by roads on wildlife

populations (Laurance et al. 2014). Quantifying and characterising the vulnerability of

species and demographic components to collisions is vital for making successful

management interventions (Lunney et al. 2008; Valero et al. 2015), based on both

habitat and road features and all other relevant spatial and temporal components

63 (Ramp et al. 2005).

64 In this context, we sought to demonstrate an integrative framework of: (i) road survey for wildlife-vehicle risk profiling and (ii) a complementary approach to predictive modelling, using machine learning to identify the features associated with a higher risk of wildlife-vehicle collisions using targeted field data. Linear regression has been 
environmental attributes (Tejera et al. 2018). This method has the advantage of

being simple to fit and easy to interpret (James et al. 2014). However, the drivers of

road mortality and its spatial pattern typically include interactions and non-linearities

that are not well represented with linear models (Cutler et al. 2007). Tree-based

algorithms (e.g., random forests: Breiman 2001), which are able to handle multi-

dimensional data and can selectively disregard irrelevant descriptors, are better

equipped to deal with such data (Svetnik et al. 2003). Random forests uses out-of-

bag sampling to estimate generalisation error (and thus reduce variance whilst

avoiding overfitting), via random variable selection and averaged trees (Diaz-Uriarte

and de Andres 2006). In this road-kill study we used random forests to deal with a

mixture of categorical and continuous variables, whilst retaining an ease-of-

interpretability (Bourel and Segura 2018). For comparison, we also fit the data using

lasso logistic regression (Hastie et al. 2009), which is a generalized linear model with

a coefficient shrinkage method.

83 Our case study was undertaken in Tasmania, the southernmost state of Australia, which is infamous for its high rate of road-kill (it is known informally as the 'road-kill capital of Australia': Bell 2012). Past research found that live abundance was not associated with the road-kill rate of several marsupial species within Tasmania (Nguyen et al. 2019). Therefore, for this study we investigated road and environmental features like traffic volume, road shape, surrounding vegetation and distance to human settlements, which are known to be associated with road-kill rates

90 (Bond and Jones 2014; Rytwinski and Fahrig 2012). Our focal species were three iconic, large-bodied marsupials: the rufous-bellied pademelon (Thylogale billardierii), Bennett's wallaby (Macropus rufogriseus) and the bare-nosed wombat (Vombatus ursinus). These animals were previously found to be the frequent victims of vehicles 
94 (based on Hobday 2010). The pademelon now is solely restricted to the island of

95 Tasmania (it became extinct on mainland Australia in the $19^{\text {th }}$ century); the other two

96 are subspecies with extant mainland counterparts. These herbivores prefer higher-

97 quality habitats (Roger et al. 2007) and are still considered locally abundant

98 (Driessen and Hocking 1992). However, they are now threatened by land-

99 use/climate change, population suppression (e.g., culling as agricultural pests), and

100 disease epidemics such as mange (Simpson et al. 2016). As such, additional road

101 mortality poses a substantial risk to their long-term viability-and needs better

102 contextualization with a strong evidence base for interventions.

\section{Methods}

Survey protocol

106

The road-kill monitoring was done in two rural regions of southern Tasmania that are subject to relatively high traffic volumes near the state capital of Hobart: the Huon Valley and Tasman Peninsula. Eight stretches of road (Fig. 1) were chosen for the surveys, four in each region. Based on the recommendations from previous road-kill studies in Australia (Lee et al. 2004; Ramp et al. 2006; Roger et al. 2011), each route was set at $15 \mathrm{~km}$ length (Fig. 1), covering a section of the roads with high speed limits (80-100 km/h).

Road-kill data were collected during four separate periods: September-early October 2016 (spring), January 2017 (summer), March 2017 (autumn) and July 2017 (winter). Data collection was done over a two-day period and repeated for four consecutive weeks across each season. On the first and third weeks, the routes were travelled according to their designated order (Fig. 1). The order was reversed on the second 
and fourth weeks, to ensure that both sides of each road were travelled equally, minimising the chance of missed observations. The roads were surveyed by two people, both spotting the animals, using a 4WD or SUV driven at low speed ( 40 $\mathrm{km} / \mathrm{h}$ ) along the designated routes.

The vehicle was stopped for each road-kill. If it was identified as one of the target species, then the location was determined using a Garmin eTrex 30 hand-held GPS unit and recorded with a unique waypoint (WGS84 geodetic datum). Sex and species were recorded when possible. A metric tape measure was used for body, head and foot (pes) length. A separate survey was done to record road features every $50 \mathrm{~m}$ along the route (see Road features as spatial predictors). Each road-kill was labelled to permit estimation of removal rates and to avoid double-counting. Each animal observation was matched against the nearest $50 \mathrm{~m}$ road features at the desktop.

\section{Quantifying removal rates and seasonal/sex biases in frequency data}

The first week of road-kill counts in each season represented bodies at various stages of decomposition, which had accumulated over an unknown prior period. Residence time on the road was dependent on both the rate of decomposition and the deliberate removal of dead animals by people or scavengers. Consequently, a high count in week one could (for instance) be attributed to many road fatalities, a low removal rate, or both. By contrast, for weeks two to four, both the number of new additions and the disappearance of previously recorded bodies during the past week were known (because each specimen was individually tagged/geo-located), resulting in direct information on accumulation and removal rates for the periods spanning weeks $1-2,2-3$ and $3-4$, for each season. These data enabled us to estimate the 
number of animals that were never observed (i.e., those killed but subsequently removed between sampling times). Taken together, these multiple lines of evidence on biases allowed for the calculation of a re-calibrated count for each season (i.e., adjusted for weekly variation in removal rates and missing observations).

Contingency tables were used to summarise sex biases in road-kill across four seasons for the three species. Differences in category counts were evaluated statistically using Fisher's exact binomial test (Suissa and Shuster 1985), with an expected (null) sex ratio of $50 \%$. A chi-squared test was used to determine whether the number of road-kill were distributed randomly across seasons (Rorden et al. 2007).

\section{Data specification for spatial analysis}

The dependent variable for the modelling was presence or absence of wildlife fatalities at a given location, with the predictors being both categorical (habitat, road and fence) and continuous (human population density (pop) and distance to fresh water (DFW). Habitat was classified as either FF = forest on both sides of the road, $\mathrm{FO}=$ forest on one side, open on the other, or $\mathrm{OO}=$ open on both sides. Road shape was designated 'straight' = S or 'curved' = C, and a roadside verge fence was noted as present or absent. Regularly spaced background points were generated at $50 \mathrm{~m}$ intervals along the designated routes, using ArcGIS on a shapefile of Tasmanian roads, which resulted in a total of 2, 491 points. Each regular point was assessed (both on-ground and via examination of high-resolution satellite imagery via Google Earth) for habitat and road characteristics. Human population density was extracted from data obtained from the Center for International Earth Science Information Network (ciesin.org) and distance to water was processed in ArcGIS 10.4. To use as (pseudo)absence points in the modelling, the regular points were 
then filtered by (conservatively) only including the subset of points spaced at least

$200 \mathrm{~m}$ from any given road-kill record. This approach yielded a total data set of 871

road-kill-presence points and 674 pseudoabsences.

Statistical analysis of spatial predictors of wildlife-vehicle collisions

(Friedman et al. 2010). Random forests (Strobl et al. 2007) can be used as a binary

classifier with interactions: branch splitting is based on the average of many random

subsets of predictors, with the goal of decorrelating the individual trees. However,

like other tree-based machine-learning methods, the random forests algorithm can

be prone to bias in variable selection if categorical variables with many levels are included (Torsten et al. 2006). To mitigate this issue and properly account for a model structure that considers both continuous and categorical predictors that are uncorrelated, the use of an unbiased tree algorithm is recommended, along with permutation variable importance (Augustin et al. 2008; Strobl et al. 2007). For easy interpretation, we also used partial dependence plots to illustrate the relationship between the predictors and the roadkill (Visintin et al. 2016).

To evaluate the predictive power of random forests against linear models, we also fitted the data using an additive logistic regression and selected the appropriate model components and dimension using machine learning, via a lasso (least absolute shrinkage and selection operator) regularization analysis (Hastie et al. 2009). The lasso estimates an optimally scaled penalty to be applied to model coefficients, resulting in sparse models that are not overfit. This is akin to continuous subset selection, whereby the shrinkage penalty $(\lambda)$ - determined adaptively by repeated k-fold cross-validation-is chosen to minimize out-of-sample prediction 
error. Model adequacy was measured based on classification accuracy, sensitivity, specificity and the true skill statistic (balancing errors of omission and commission: Allouche et al. 2006).

\section{Results}

\section{Seasonal and sex differences in road-kill risk}

The most frequently road-killed species was the pademelon (Table 1). The raw counts of road-kills differed substantially across seasons: 201 in spring, 111 in summer, 256 in autumn and 301 in winter. Road-kills persisted longest on roads in spring and disappeared most rapidly in summer, leading to re-calibrated biascorrected counts: 124 in spring, 178 in summer, 266 in autumn and 303 in winter. The calibrated results showed no significant difference in road-kill accumulation rates between winter and autumn $(95 \% \mathrm{Cl}$ of exact binomial test $=0.426-0.509$; overlaps 0.5 null expectation), while spring had the lowest seasonal rate (autumn : spring ratio $=0.684, \mathrm{Cl}=0.635-0.730 ;$ summer $:$ spring $=0.589, \mathrm{Cl}=0.532-0.645 ;$ winter : spring $=0.710, \mathrm{Cl}=0.664-0.752)$. Autumn and winter remained the seasons with the highest road-kill for macropods post-calibration.

There was no overall sex bias in road-kill for the wallaby $(0.452, \mathrm{Cl}=0.359-0.548)$ but a slight male bias for the pademelon $(0.606, \mathrm{Cl}=0.558-0.652)$. Female pademelons were most at risk in autumn (Fig. 2a), whereas winter was the only season with a male bias $(0.744, \mathrm{Cl}=0.668-0.810)$. For the wallaby, female mortality was highest in autumn $(0.713, \mathrm{Cl}=0.610-0.801)$, and this persisted to winter (Fig. $2 b)$, with no clear peak for male-wallaby mortality, although their numbers decreased noticeably in summer and then gradually recovered (Fig. 2a, b) with a significant 
male bias in spring $(0.867, \mathrm{Cl}=0.693-0.962)$. There was no statistically meaningful

sex bias or trend for the wombat due to sparse numbers (Fig. 2c).

\section{Spatial predictors of road-kill}

219 The random forests algorithm produced a minimized out-of-bag error when three of the predictor variables were randomly sampled as candidates at each branch split.

The most consistently influential variable in the decision trees was habitat, with an importance value of 0.146 . The two continuous predictors (human population density and distance to fresh water) were the second-most selected across the treeaveraging process, yielding variable importance values of 0.117 and 0.114 respectively. The highest risk of road mortality was associated with forested areas, in locations with no fence and along curved sections of road (Fig. 3). The complex relationship between the continuous variables to road-kill presence is shown in Fig. 3 .

The overall classification accuracy of the random forests model of road-kill risk was 84.8\%: $91.3 \%$ for presences (76 errors in 871 observations) and $76.4 \%$ for pseudoabsences $(159 / 674)$, with a sensitivity $=0.833$, specificity $=0.871$, and true skill statistic $($ TSS $)=0.704$ (where TSS $=1$ is a perfect classifier, and 0 the random expectation).

For comparison, the lasso-based shrinkage of a logistic regression model rejected all but two categorical predictors to derive the most parsimonious model (at $\lambda=0.024$; Fig. 4): habitat (coefficients relative to FF were: $\beta_{F O}=0.613$ and $\beta_{O O}=0.063$ ) and fence (coefficient relative to no fence, $\beta_{\text {fence }}=0.470$ ). As such, risk of vehicle fatality

237 in this linear-additive model was predicted to be highest in habitats with a mix of 238 forest and open areas with the road bordered by fences. The lasso-model classification accuracy for road-kill location was, however, markedly lower than that 
240 for the random forests, at $61.2 \%$ overall: $76.1 \%$ for presences and $42.0 \%$ for

241 pseudoabsences, with a sensitivity $=0.629$, specificity $=0.576$, and true skill statistic

$242=0.205$ (i.e., a bias towards over-estimating the likelihood of road-kill at a location).

\section{Discussion}

245 Machine-learning approaches to spatial analysis of road-kill risk

246 In this road-kill study, the random forests classification algorithm was clearly superior

247 to lasso-logistic model for predicting the riskiness of locations for wildlife-vehicle

248 collisions. The lasso-regularization of a generalized linear model disregarded both

249 continuous variables (distance to freshwater and population), retaining only two

250 categorical variables: habitat and fence. However, as illustrated by the partial

251 dependence plots (Fig. 3), distance to freshwater and population clearly displayed a

252 non-linear relationship to road mortality, which explained why they could not be

253 captured in the additive logistic model. This model-algorithm comparison shows the

254 value of tree-based machine-learning approaches to developing more complex (yet

255 parsimonious and data-driven) models for analysing road mortality data with non-

256 linearities are plausible.

257 Additionally, the random forests approach is able to implicitly account for feature

258 interactions in the data without the need to manually identify and include specific

259 terms in the model, thus reducing the need for hand-crafted a priori specification

260 (Thuiller et al. 2009; Wright et al. 2016) of interactions. On the other hand, random

261 forests is less effective in dealing with linear relationships, and linear models can be

262 better at interpolating data (Thuiller et al. 2009). Furthermore, the output of random

263 forests is comparatively harder to interpret than that of generalized linear models, 
becoming more complicated as the number of nodes increases. While partial

interactions (Cutler et al. 2007). Therefore, prior to selecting the appropriate analysis,

it is crucial that the purpose of the study be considered. Is it to analyse the most

important predictors for road-kill? Is it to extrapolate the data and predict the rate of

road-kill in similar areas? This decision can guide the appropriateness of the method(s) selected for modelling.

271 Regarding the specific results of this case study in Tasmania, the macropod species

leave their diurnal shelters, located in closed habitats (e.g., native forests,

established plantations), to forage in more open adjacent areas (e.g., grassland, intuitively have the highest rates of road-kill (and this was predicted by the lasso-

278 logistic). However, when interactions are considered (in random forests), forested areas were found be at highest risk. One explanation might be that forested areas were typically located further from populated areas, leading to changes in driver attitude as speed limits increased (based on Hobday 2010). It is likely that animal behaviour (e.g., foraging routes, preference for well-vegetated roadside verges) would also change with regards to proximity to fresh water and availability of pastures across mixed-agricultural lands.

Most of the surveyed routes adjacent to farmland and plantations were fenced off using stock races, which has been found to correlate positively with the frequency of 
288 frequency of animal-vehicle collisions have been found to be both positive and negative, often depending on its type, suitability to the target-species ecology, and

290 the state of maintenance (Polak et al. 2014). Therefore, a fencing-to-mitigate strategy might not be appropriate if the target-species have widely different ecologies,

292 lowering risk for one but increasing it for another.

\section{Seasonal and autecological influences on road-kill rates}

294 The fewest road-kills were seen in summer, for all species. This result appears to 295 agree with the hypothesis that a longer day length reduces the number of animalvehicle collisions, because the largely crepuscular/nocturnal habits of Australian mammals lead to most road-kills occurring during the dusk-to-dawn period, when animals have commenced foraging but vehicle activity is still relatively high (Ellis et al. 2016). However, we were able to estimate higher decomposition rates of summer, likely due to warmer temperatures and higher insect abundance (Campobasso et al. 2001), along with the more rapid removal of roadkill by roadside-management organisations during peak tourist seasons. After taking into consideration this higher rate of road-kill removal via data calibration, our results revealed no difference between spring and summer collision frequency for the wallaby, with a slightly higher rate in summer compared to spring for the pademelon. As such, the nocturnaloverlap-risk hypothesis is only weakly supported by our corrected data.

The striking increase in female counts in autumn for the macropod species coincides with the peak period of parturition (Curlewis 1989). Female macropods in oestrous tend to increase their mobility to enhance their exposure to males (Fisher and Lara 1999). Another study showed that female wallabies in southern Australia also 
312 harsher weather driving them to move to access more resources (Johnson 1987).

313 Consequently, their chance encounter rate with roads is likely to be higher over this

314 period, leading to more vehicle collisions. By contrast, in spring and summer,

315 females of both species tend to restrict their movements when joeys leave the pouch

316 (Rubenstein and Wrangham 1986), resulting in lower road-kill counts. The road-kill

317 analysis of the bare-nosed wombats (Vombatus ursinus) was constrained due to the

318 small and regionally restricted sample sizes, prohibiting any robust interpretation of

319 trends.

Requirements for further targeted research

321 Past road-kill research has faced an obvious trade-off. Studies that survey multiple

stretches of roads had robust spatial coverage but limited temporal implications

(Mallick et al. 1998; Russell et al. 2009), whereas those that lacked an explicit spatial

contrast usually compensated with a more frequent and consistent approach to

surveying (Ramp et al. 2005; Roger et al. 2011). Our approach sought to reach an

acceptable middle ground: repeatedly surveying enough short segments of roads to

yield a broad spatial coverage across all seasons, along with marking and

geolocating the wildlife corpses to permit explicit estimation of biases and improve

the overall systematic rigor of the surveys. We have provided our data and the

random forests predictive model to the relevant wildlife and road-management

authorities in Tasmania, to help guide future planning and decision making.

332 The ultimate goal of investigating road mortality in animals-besides determining

333 correlating/causal factors and using these for prediction and intervention-is to

334 understand any possible effect that this additive death rate has on absolute

335 population viability, particularly for species threatened by other risks (Roger et al. 
336 2011). An increase in the loss of female macropods during oestrous in autumn could

337 have fitness implications for recruitment in local populations, especially if new threats

338 (e.g., accidental introduction of the red fox, Vulpes vulpes) threaten future

339 demographic stability. However, this effect, and any similar sex biases or seasonal

340 trends, could only be reasonably used to predict the effect of road mortality on

341 populations when other autecological information are well understood (Ramp et al.

342 2005). For (most) situations in road ecology, detailed demographic data on the underpinnings of population viability (e.g., density-dependence, habitat suitability, age-specific vital rates), are lacking, making it difficult to determine additive or compensatory effects of vehicle-collision mortality, especially as an interaction with other drivers of population dynamics. A future synergy of mechanistic viability modelling and targeted field studies, spanning space (e.g., near and distant from roads) and time, is clearly ideal. That said, we have here demonstrated that advanced approaches to the modelling of pattern-based information on road-kill can still lead to useful and nuanced insights on relative risk, and thereby offer a guide to practical management interventions that can mitigate these hazards.

Acknowledgements

We would like to thank Dr. Emily Flies, Dr Stefania Ondei and Dr Sanghyun Hong for their valuable inputs. Research was funded by ARC grant FL160100101. Road-kill data were collected under the University of Tasmania animal ethics permit A0015929.

\section{Conflicts of Interest}

359 The authors declare no conflicts of interest. 


\section{References}

362 Allouche, O., Tsoar, A., and Kadmon, R. (2006). Assessing the accuracy of species

363 distribution models: Prevalence, kappa and the true skill statistic (TSS). Journal of

364 Applied Ecology 43, 1223-1232.

366 Augustin, T., Kneib, T., Boulesteix, A.-L., Strobl, C., and Zeileis, A. (2008).

367 Conditional variable importance for random forests. BMC Bioinformatics 9, 307. doi:

10.1186/1471-2105-9-307.

Barthelmess, E. L. (2014). Spatial distribution of road-kills and factors influencing

road mortality for mammals in Northern New York State. Biodiversity and

Conservation 23, 2491-2514. doi: 10.1007/s10531-014-0734-2.

374 Bell, C. (2012). Colliding human-animal trajectories (road kill!) on a Tasmanian

375 journey. Critical Arts: A South-North Journal of Cultural \& Media Studies 26, 272-289.

376 doi: 10.1080/02560046.2012.705457.

378 Bond, A. R. F. and Jones, D. N. (2014). Roads and macropods: interactions and

379 implications. Australian Mammalogy 36, 1-14. doi: 10.1071/am13005.

381 Bourel, M. and Segura, A. M. (2018). Multiclass classification methods in ecology. 
384 Breiman, L. (2001). Random Forests. Machine Learning 45, 5-32. doi:

385 10.1023/a:1010933404324.

387 Campobasso, C. P., Di Vella, G., and Introna, F. (2001). Factors affecting

388 decomposition and Diptera colonization. Forensic Science International 120, 18-27.

389 doi: 10.1016/s0379-0738(01)00411-x.

391 Curlewis, J. D. (1989). The breeding-season of Bennett's wallaby (Macropus

392 rufogriseus rufogriseus) in Tasmania. Journal of Zoology 218, 337-339. doi:

$393 \quad 10.1111 / \mathrm{j} .1469-7998.1989 . t b 02545 . x$.

395 Cutler, D. R., Edwards Jr, T. C., Beard, K. H., Cutler, A., Hess, K. T., Gibson, J., and 396 Lawler, J. J. (2007). Random forests for classification in ecology. Ecology 88, 27832792. doi: 10.1890/07-0539.1.

399 Diaz-Uriarte, R. and de Andres, S. A. (2006). Gene selection and classification of 400 microarray data using random forest. BMC Bioinformatics 7. doi: 10.1186/1471$401 \quad 2105-7-3$.

403 Driessen, M. M. and Hocking, G. J. (1992) 'Review and Analysis of Spotlight Surveys 404 in Tasmania, 1975-1990.' (Department of Parks, Wildlife and Heritage Australia.)

406 Ellis, W. A., FitzGibbon, S. I., Barth, B. J., Niehaus, A. C., David, G. K., Taylor, B. D., 407 Matsushige, H., Melzer, A., Bercovitch, F. B., Carrick, F., Jones, D. N., Dexter, C., 
408 Gillett, A., Predavec, M., Lunney, D., and Wilson, R. S. (2016). Daylight saving time

can decrease the frequency of wildlife-vehicle collisions. Biology Letters 12, 5. doi:

410

10.1098/rsbl.2016.0632.

412 Elzanowski, A., Ciesiolkiewicz, J., Kaczor, M., Radwanska, J., and Urban, R. (2009).

413 Amphibian road mortality in Europe: a meta-analysis with new data from Poland.

414 European Journal of Wildlife Research 55, 33-43. doi: 10.1007/s10344-008-0211-x.

416 Evans, M. C., Macgregor, C., and Jarman, P. J. (2006). Diet and feeding selectivity

417 of common wombats. Wildlife Research 33, 321-330. doi: 10.1071/wr05047.

419 Fielding, M. W., Buettel, J. C., Nguyen, H., and Brook, B. W. (2020). Ravens exploit

420 wildlife roadkill and agricultural landscapes but do not affect songbird assemblages.

421 Emu - Austral Ornithology 120, 11-21. doi: 10.1080/01584197.2019.1629820.

423 Fisher, D. O. and Lara, M. C. (1999). Effects of body size and home range on access

424 to mates and paternity in male bridled nailtail wallabies. Animal Behaviour 58, 121-

425 130. doi: 10.1006/anbe.1999.1119.

427 Forman, R. T. T. and Alexander, L. E. (1998). Roads and their major ecological 428 effects. Annual Review of Ecology and Systematics 29, 207-231. 
430 Friedman, J., Hastie, T., and Tibshirani, R. (2010). Regularization Paths for

431 Generalized Linear Models via Coordinate Descent. Journal of statistical software 33,

$432 \quad 1-22$.

434 Gibbs, J. P. and Shriver, W. G. (2002). Estimating the effects of road mortality on

435 turtle populations. Conservation Biology 16, 1647-1652. doi: 10.1046/j.1523-

$436 \quad 1739.2002 .01215 . x$

438 Hastie, T., Friedman, J., and Tibshirani, R. (2009) 'The Elements of Statistical

439 Learning : Data Mining, Inference and Prediction.' 2nd edn. (N.Y. : Springer.: New

440 York.)

442 Hobday, A. J. (2010). Nighttime driver detection distances for Tasmanian fauna:

443 informing speed limits to reduce roadkill. Wildlife Research 37, 265-272. doi:

$444 \quad 10.1071 /$ wr09180.

446 Hothorn, T., Hornik, K., and Zeileis, A. (2006). Unbiased Recursive Partitioning: A

447 Conditional Inference Framework. Journal of Computational and Graphical Statistics

448 15, 651-674. doi: 10.1198/106186006X133933.

450 James, G., Witten, D., Hastie, T., and Tibshirani, R. (2014) 'An Introduction to

451 Statistical Learning: with Applications in R.' (Springer Publishing Company,

452 Incorporated.) 
454 Johnson, C. N. (1987). Macropod studies at wallaby creek. IV. Home range and

455 movements of the red-necked wallaby. Australian Wildlife Research 14, 125-132. doi:

$456 \quad 10.1071 /$ WR9870125.

458 Laurance, W. F., Clements, G. R., Sloan, S., O'Connell, C. S., Mueller, N. D.,

459 Goosem, M., Venter, O., Edwards, D. P., Phalan, B., Balmford, A., Van Der Ree, R., and Arrea, I. B. (2014). A global strategy for road building. Nature 513, 229-232. doi: 10.1038/nature13717.

le Mar, K. and McArthur, C. (2005). Comparison of habitat selection by two sympatric macropods, Thylogale billardierii and Macropus rufogriseus rufogriseus, in a patchy eucalypt-forestry environment. Austral Ecology 30, 674-683. doi: 10.1111/j.14429993.2005.01510.x.

Lee, E., Klocker, U., Croft, D. B., and Ramp, D. (2004). Kangaroo-vehicle collisions

in Australia's sheep rangelands, during and following drought periods. Australian

Mammalogy 26, 215-226. doi: 10.1071/AM04215.

472 Loss, S. R., Will, T., and Marra, P. P. (2014). Estimation of bird-vehicle collision

473 mortality on U.S. roads. Journal of Wildlife Management 78, 763-771. doi:

$474 \quad 10.1002 / j w m g .721$. 
476 Lunney, D., Munn, A. J., and Meikle, W. (2008) 'Too Close for Comfort: Contentious

477 Issues in Human-Wildlife Encounters.' (Royal Zoological Society of New South

478 Wales: Australia.)

479

480 Mallick, S. A., Hocking, G. J., and Driessen, M. M. (1998). Road-kills of the eastern

481 barred bandicoot (Perameles gunnii) in Tasmania: an index of abundance. Wildlife

482 Research 25, 139-145. doi: 10.1071/wr96119.

484 Nguyen, H. K. D., Fielding, M. W., Buettel, J. C., and Brook, B. W. (2019). Habitat

485 suitability, live abundance and their link to road mortality of Tasmanian wildlife.

486 Wildlife Research 46, 236-246. doi: 10.1071/wr18128.

488 Polak, T., Rhodes, J. R., Jones, D., and Possingham, H. P. (2014). Optimal planning 489 for mitigating the impacts of roads on wildlife. Journal of Applied Ecology 51, 726-

490 734. doi: 10.1111/1365-2664.12243.

492 Ramp, D., Caldwell, J., Edwards, K. A., Warton, D., and Croft, D. B. (2005).

493 Modelling of wildlife fatality hotspots along the snowy mountain highway in New

494 South Wales, Australia. Biological Conservation 126, 474-490. doi:

$495 \quad$ 10.1016/j.biocon.2005.07.001.

497 Ramp, D., Wilson, V. K., and Croft, D. B. (2006). Assessing the impacts of roads in 498 peri-urban reserves: road-based fatalities and road usage by wildlife in the Royal 
499 National Park, New South Wales, Australia. Biological Conservation 129, 348-359.

500

doi: 10.1016/j.biocon.2005.11.002.

501

502 Roger, E., Laffan, S. W., and Ramp, D. (2007). Habitat selection by the common

503 wombat (Vombatus ursinus) in disturbed environments: Implications for the

504 conservation of a 'common' species. Biological Conservation 137, 437-449. doi:

$505 \quad$ 10.1016/j.biocon.2007.03.001.

507 Roger, E., Laffan, S. W., and Ramp, D. (2011). Road impacts a tipping point for

508 wildlife populations in threatened landscapes. Population Ecology 53, 215-227. doi:

$509 \quad 10.1007 / \mathrm{s} 10144-010-0209-6$.

511 Rorden, C., Karnath, H. O., and Bonilha, L. (2007). Improving lesion-symptom

512 mapping. Journal of Cognitive Neuroscience 19, 1081-1088. doi:

$513 \quad 10.1162 / j o c n .2007 .19 .7 .1081$.

515 Rubenstein, D. and Wrangham, R. (1986) 'Ecological Aspects of Social Evolution:

516 Birds and Mammals.' (Princeton University Press: USA.)

518 Russell, T. C., Herbert, C. A., and Kohen, J. L. (2009). High possum mortality on

519 urban roads: implications for the population viability of the common brushtail and the

520 common ringtail possum. Australian Journal of Zoology 57, 391-397. doi:

$521 \quad 10.1071 /$ zo09079. 
523 Rytwinski, T. and Fahrig, L. (2012). Do species life history traits explain population

524 responses to roads? A meta-analysis. Biological Conservation 147, 87-98. doi:

$525 \quad$ 10.1016/j.biocon.2011.11.023.

527 Simpson, K., Johnson, C. N., and Carver, S. (2016). Sarcoptes scabiei: the mange 528 mite with mighty effects on the common wombat (Vombatus ursinus). PLoS ONE 11, e0149749-e0149749. doi: 10.1371/journal.pone.0149749.

531 Skorka, P. (2016). The detectability and persistence of road-killed butterflies: an 532 experimental study. Biological Conservation 200, 36-43. doi:

533 10.1016/j.biocon.2016.05.026.

535 Strobl, C., Boulesteix, A.-L., Zeileis, A., and Hothorn, T. (2007). Bias in random 536 forest variable importance measures: Illustrations, sources and a solution. BMC 537 Bioinformatics 8, 25. doi: 10.1186/1471-2105-8-25.

539 Suissa, S. and Shuster, J. J. (1985). Exact unconditional sample sizes for the $2 \times 2$ 540 binomial trial. Journal of the Royal Statistical Society. Series A (General) 148, 317541 327. doi: $10.2307 / 2981892$.

543 Svetnik, V., Liaw, A., Tong, C., Culberson, J. C., Sheridan, R. P., and Feuston, B. P. 544 (2003). Random forest: A classification and regression tool for compound 545 classification and QSAR modeling. Journal of Chemical Information and Computer 546 Sciences 43, 1947-1958. doi: 10.1021/ci034160g. 
548 Tejera, G., Rodriguez, B., Armas, C., and Rodriguez, A. (2018). Wildlife-vehicle

549 collisions in Lanzarote Biosphere Reserve, Canary Islands. PLoS ONE 13. doi:

550 10.1371/journal.pone.0192731.

552 Thuiller, W., Araújo, M. B., and Lavorel, S. (2009). Generalized models vs.

553 classification tree analysis: Predicting spatial distributions of plant species at different

554 scales. Journal of Vegetation Science 14, 669-680. doi: 10.1111/j.1654-

555 1103.2003.tb02199.x.

557 Torsten, H., Kurt, H., and Achim, Z. (2006). Unbiased Recursive Partitioning: A

558 Conditional Inference Framework. Journal of Computational and Graphical Statistics,

559 651. doi: 10.1198/106186006X133933.

561 Trombulak, S. C. and Frissell, C. A. (2000). Review of ecological effects of roads on

562 terrestrial and aquatic communities. Conservation Biology 14, 18-30.

564 Valero, E., Picos, J., and Alvarez, X. (2015). Road and traffic factors correlated to

565 wildlife-vehicle collisions in Galicia (Spain). Wildlife Research 42, 25-34. doi:

$56610.1071 /$ wr14060.

568 Visintin, C., van der Ree, R., and McCarthy, M. A. (2016). A simple framework for a 569 complex problem? Predicting wildlife-vehicle collisions. Ecology and Evolution 6, 570 6409-6421. doi: 10.1002/ece3.2306. 
572 Wiggins, N. L. and Bowman, D. (2011). Macropod habitat use and response to

573 management interventions in an agricultural-forest mosaic in north-eastern

574 Tasmania as inferred by scat surveys. Wildlife Research 38, 103-113. doi:

$575 \quad 10.1071 /$ wr10116.

576

577 Wright, M. N., Ziegler, A., and Konig, I. R. (2016). Do little interactions get lost in

578 dark random forests? BMC Bioinformatics 17, 10. doi: 10.1186/s12859-016-0995-8.

579

580 
581 Table 1. Total road-kill frequency (counts) of the rufous-bellied pademelon (Thylogale

582 billardierii), Bennett's wallaby (Macropus rufogriseus) and bare-nosed wombat

583 (Vombatus ursinus) surveyed along $8 \times 15 \mathrm{~km}$ roads across four weeks within each

584 season (spring, summer, autumn and winter) of southern Tasmania, during 2016-2017.

585 Unsexed animals were too macerated or dismembered to permit assignment of a

586 gender.

\begin{tabular}{lcccc}
\hline Species & Male & Female & Unsexed & Total \\
\hline T. billardierii & 261 & 170 & 217 & 648 \\
M. rufogriseus & 63 & 52 & 63 & 178 \\
V. ursinus & 10 & 14 & 19 & 43 \\
& & & & \\
\hline
\end{tabular}

587 


\section{Figure legends}

589 Fig. 1. Geographic location of the road-kill surveys in southern Tasmania. The black 590 line represents the driving route, and the red lines mark the $8 \times 15 \mathrm{~km}$ survey roads.

$591 \mathrm{H}=$ Huon Valley, $\mathrm{T}=$ Tasman Peninsula. $1(\mathrm{H}-\mathrm{F})=$ Fern Tree, $2(\mathrm{H}-\mathrm{N})=$ North Huon, $5923(\mathrm{H}-\mathrm{C})$ Cygnet, $4(\mathrm{H}-\mathrm{R})=$ Nicholls Rivulet, $5(\mathrm{~T}-\mathrm{S})=$ Sorell, $6(\mathrm{~T}-\mathrm{N})=$ Nubeena, 7

$593(\mathrm{~T}-\mathrm{P})=$ Port Arthur, $8(\mathrm{~T}-\mathrm{B})=$ Buckland.

595 Fig. 2. Seasonal variation in total abundance and sex bias of marsupial road-kills in 596 southern Tasmania in 2016-2017, showing results before and after the observational 597 calibration (to account for removals and missed observations). Plotted are: a) 598 Thylogale billardierii, b) Macropus rufogriseus and c) Vombatus ursinus. Raw and 599 calibrated bars are expressed as each season's fraction of the total count; lines 600 show the proportion of each sex found in a given season relative to all seasons. 601

602 Fig 3. Partial dependence plots of the predictors on the road-kill rate of the three 603 Tasmanian marsupials, derived from a machine-learning algorithm fitted using 604 random forests.

Fig 4. Lasso-based regularization of an additive logistic-regression model, showing 607 changes in the model coefficients with respect to the lasso-shrinkage parameter 608 (lambda); also shown are number of retained coefficients (above the plot window). 609 The dashed vertical red line is the value of lambda that minimized the crossvalidation error, which resulted in a sparse three-parameter model of habitat (forestopen, open-open) and fence (present) relative to the forest-forest/fence-absent base model. All other predictors were shrunk to zero. 


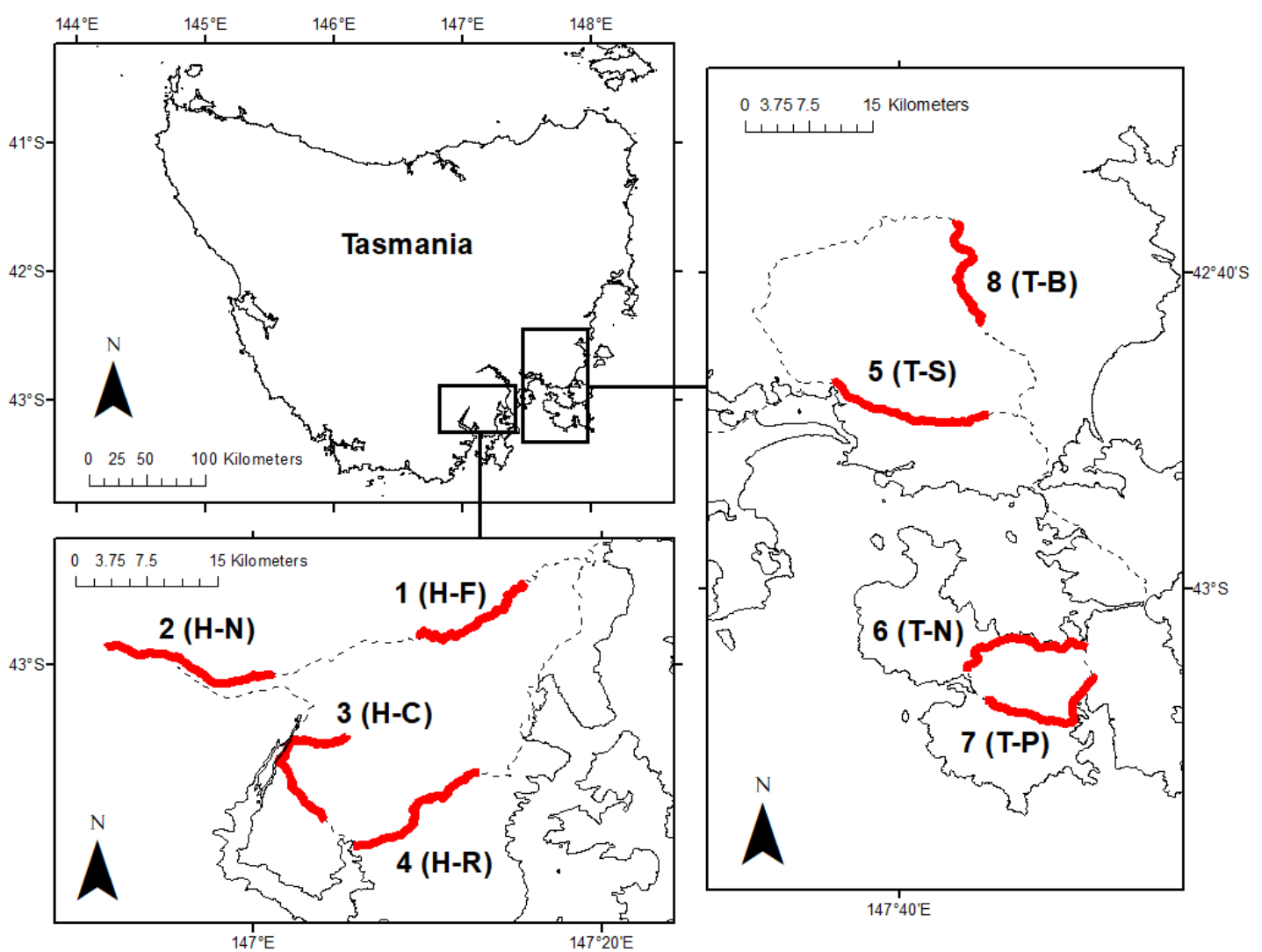


bioRxiv preprint doi: https://doi.org/10.1101/2021.01.17.427044; this version posted January 19,2021 . The copyright holder for this preprint (which was not certified by peer review) is the author/funder, who has granted bioRxiv a license to display the preprint in perpetuity. It is made available under aCC-BY-NC-ND 4.0 International license.

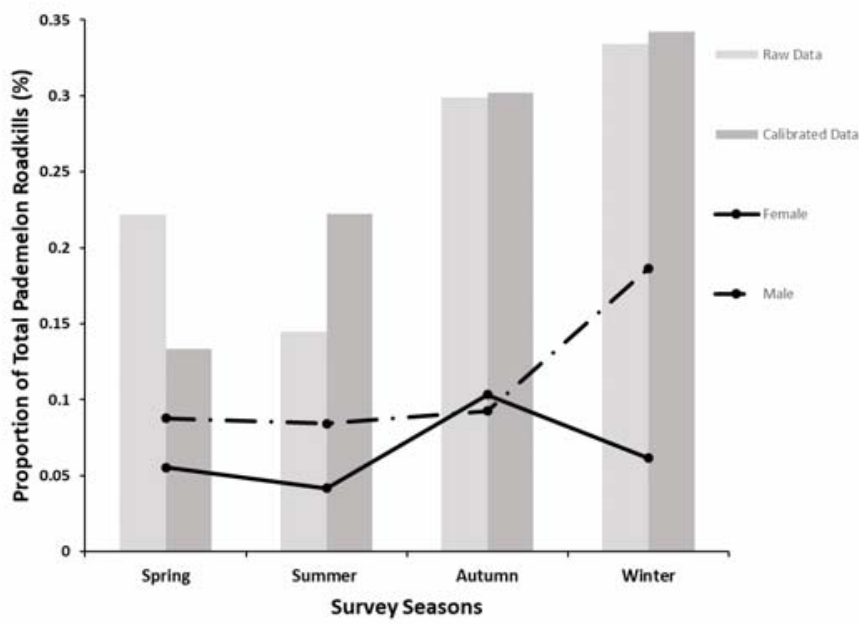

b)

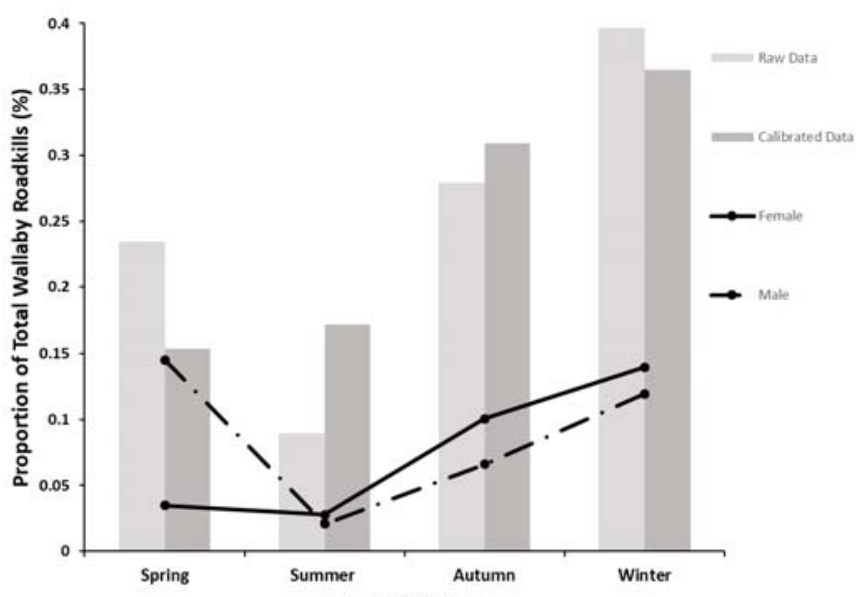

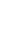

Survey Seasons

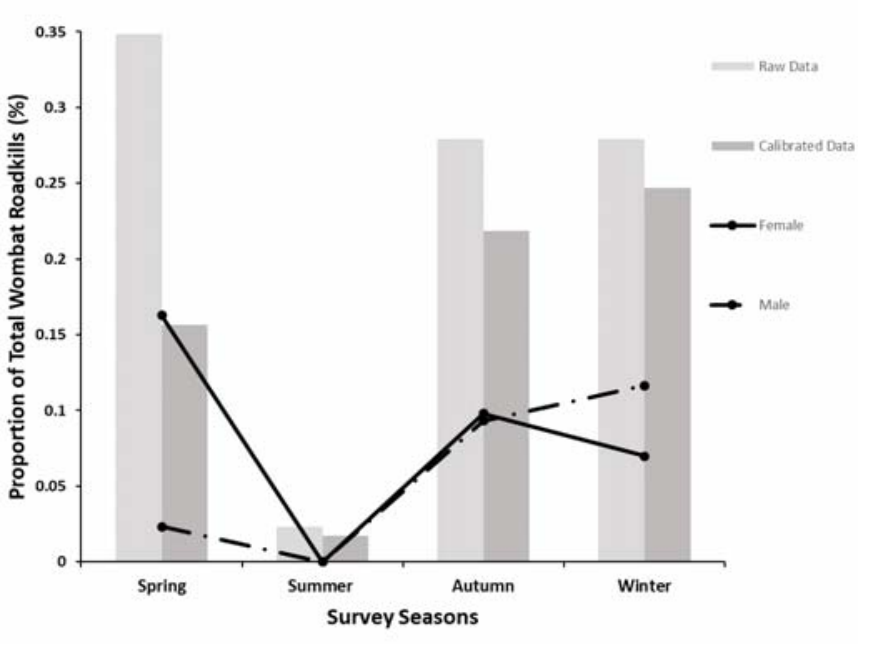

$618 \quad$ Fig. 2. 
bioRxiv preprint doi: https://doi.org/10.1101/2021.01.17.427044; this version posted January 19,2021 . The copyright holder for this preprint (which was not certified by peer review) is the author/funder, who has granted bioRxiv a license to display the preprint in perpetuity. It is made available under aCC-BY-NC-ND 4.0 International license.
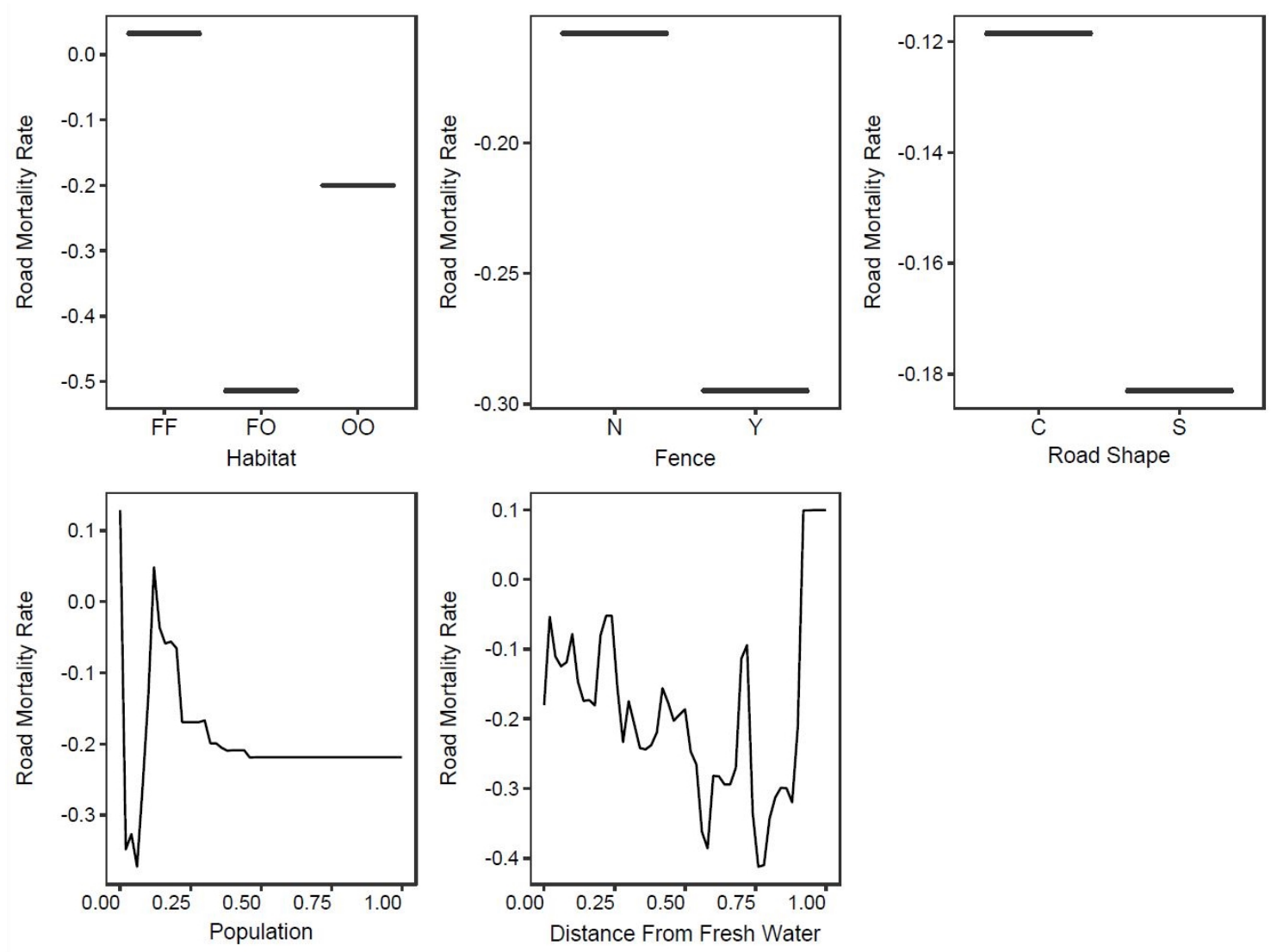

\section{$620 \quad$ Fig 3.}

621 
bioRxiv preprint doi: https://doi.org/10.1101/2021.01.17.427044; this version posted January 19, 2021. The copyright holder for this preprint (which was not certified by peer review) is the author/funder, who has granted bioRxiv a license to display the preprint in perpetuity. It is made available under aCC-BY-NC-ND 4.0 International license.

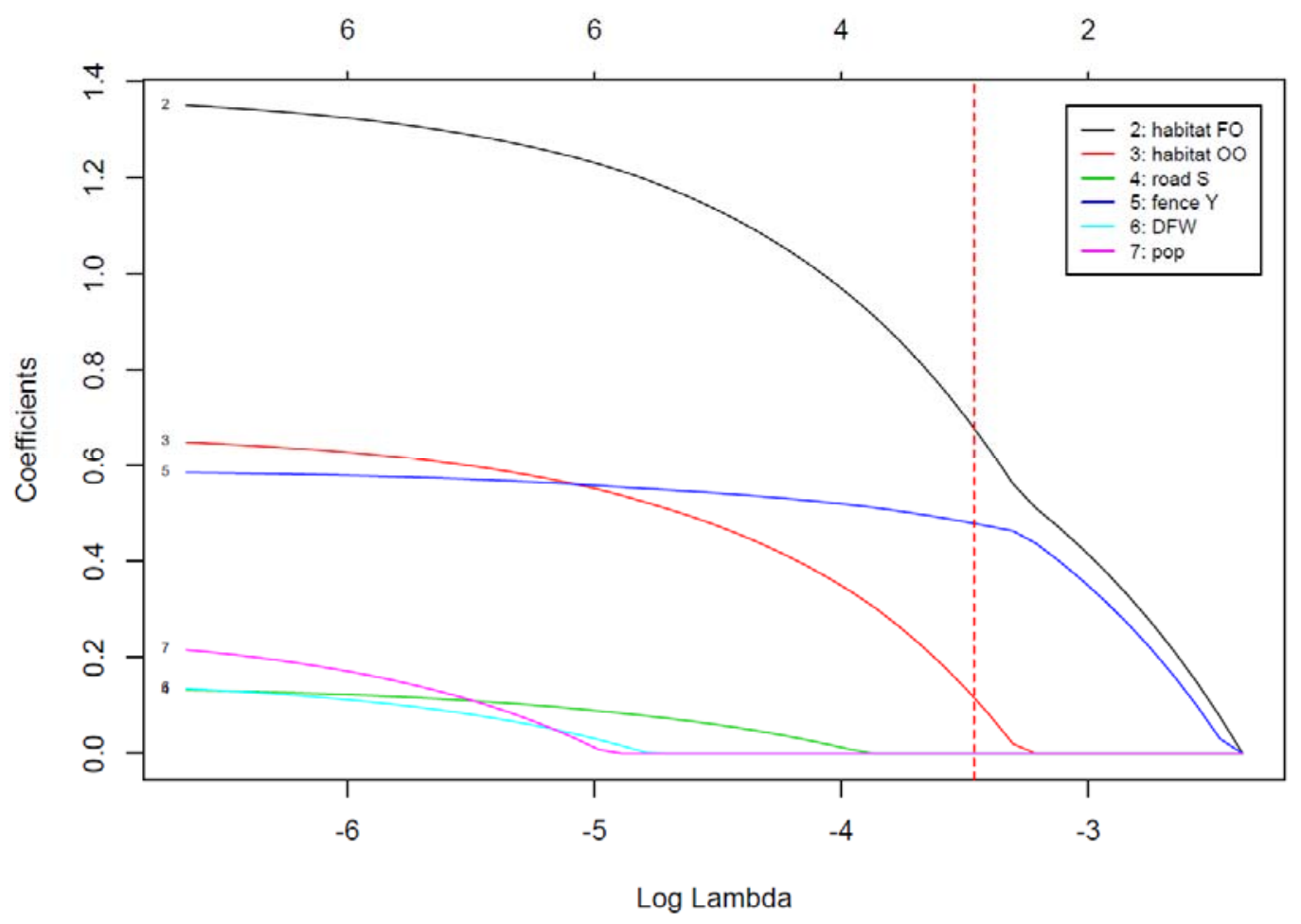

\section{$623 \quad$ Fig 4.}

